\title{
Ileal dysfunction in Crohn's disease assessed by the postprandial serum bile acid response*
}

\author{
F S SUCHY AND W F BALISTRERI† \\ From the Division of Gastroenterology, Children's Hospital Research Foundation, Cincinnati, Ohio; Department \\ of Pediatrics, University of Cincinnati, College of Medicine, Cincinnati, Ohio, USA
}

SUMMARY We assessed ileal functional integrity in 20 consecutive patients with Crohn's disease by sequential measurement of the postprandial serum bile acid concentration. In all 14 patients with active Crohn's disease involving the terminal ileum, the mean $( \pm S E M)$ peak response in the cholylglycine $(0.4 \pm 0.04 \mu \mathrm{mol} / \mathrm{l}, \mathrm{n}=14)$ as well as in the total serum bile acid concentration $(2 \cdot 0 \pm 0.4 \mu \mathrm{mol} / 1, \mathrm{n}=10)$ was similar to that seen in a group of children who had undergone ileal resection. A significantly greater increase in the cholylglycine $(1 \cdot 8 \pm 0.18 \mu \mathrm{mol} / \mathrm{l}, \mathrm{n}=16, \mathrm{P}<0.01)$ and in the total serum bile acid concentration $(9.8 \pm 2.4 \mu \mathrm{mol} / \mathrm{l}, \mathrm{n}=11, \mathrm{P}<0.025)$ was noted in normal children. In five of the six remaining patients (three with Crohn's disease shown not to involve the ileum and two of three with asymptomatic, treated Crohn's ileitis) and in seven patients with ulcerative colitis, the meal stimulated responses were normal. These preliminary results suggest that measurement of the serum bile concentration after a meal stimulus may provide a valuable index of ileal inflammation in patients with Crohn's disease.

Crohn's disease in children frequently involves the terminal ileum, the site of bile acid active transport. ${ }^{2}$ Several studies have suggested that ileal inflammation may interfere with the enterohepatic circulation of bile acids. ${ }^{3-8}$ Our aim in this study was to assess ileal function in patients with Crohn's disease by measuring the meal stimulated response of the serum bile acid concentration. The advent of reliable radioimmunoassays for bile acids in serum allows investigation of bile acid pathophysiology in intestinal disease, as the small changes in concentration that occur in the postprandial state can be precisely measured..$^{9-12}$

\section{Methods}

\section{SUBJECTS}

Twenty consecutive patients with Crohn's disease were studied. Ten patients (nine children with an age range of 9 to 17 years and one adult, aged 34 years) had newly diagnosed, untreated Crohn's disease. Radiographic abnormalities involved the terminal

*Presented in part at the annual meeting of the American Gastroenterological Association, New Orleans, LA, 23 May 1979, and published in abstract form. ${ }^{1}$

†Address for correspondence: W F Balistreri, Children's Hospital Research Foundation, Elland and Bethesda Avenues, Cincinnati, Ohio 45229, USA.

Received for publication 12 May 1981 ileum in seven patients and were limited to the upper small bowel in three patients. In this group disease activity was assessed by the National Cooperative Study Crohn's Disease Activity Index, in which a value greater than 150 indicates active disease. ${ }^{13}$ The mean score in these patients was $243.1 \pm 19 \cdot 3$ $(\bar{x} \pm$ SEM $)$ at the time of the study; however, this index may possibly underestimate disease activity in some children in whom severe growth failure may be the only manifestation of Crohn's disease.

Ten patients with previously diagnosed Crohn's disease (nine children with an age range of 10 to 18 years, and one adult, aged 32 years) under standard medical thereapy for longer than six months were also studied. All patients in this group had abnormalities of the terminal ileum on radiography and none had undergone intestinal resection. Seven of these patients were studied during a period of continuing disease; three patients were completely asymptomatic.

Comparison groups included 16 healthy subjects (age range of 2 to 16 years); six patients with variable lengths of ileal resection for non-inflammatory bowel disease (age range 2 to 19 years), and seven patients with ulcerative colitis (age range 2 to 15 years). Five of the patients with colitis had symptoms with cramps and diarrhoea at the time of the study, and two of these patients had changes of 'backwash' ileitis on contrast radiographs. 
Informed consent was obtained from the parents and subjects before taking part in the study. The protocol was approved by the Institutional Review Board of the Children's Hospital Medical Center and the Scientific Advisory Committee of the General Clinical Research Center.

\section{EXPERIMENTAL DESIGN}

All subjects were admitted to the Clinical Research Center after an overnight fast of 12 hours. An indwelling butterfly needle (19-23 gauge) was left in situ after a single forearm venepuncture to allow for repeated sampling; $0.5 \mathrm{ml}$ of blood were obtained 30 minutes before, immediately before (zero time), and at 30 minute intervals for three hours after a standardised liquid meal. The needle was kept patent by intermittent irrigation with a dilute solution of heparinised saline (10 units heparin/ml).

The liquid test meal was adjusted to contain one calorie per $\mathrm{ml}$ by the addition of corn oil and dextrose to a commercial dietary supplement (Meritene, Doyle Pharmaceutical Co., Minneapolis, $\mathrm{MN}$ ); the caloric distribution was approximately $40 \%$ fat, $40 \%$ carbohydrate, and $20 \%$ protein. This mixture was administered in a volume of $10 \mathrm{ml}$ per kilogram of body weight; the entire volume (not to exceed $360 \mathrm{ml}$ ) was ingested in a five minute period. Additional food or water during the test period was prohibited.

\section{ANALYSIS}

The blood samples were allowed to clot and the serum was separated after centrifugation. The samples were stored at $-20^{\circ} \mathrm{C}$ until analysed. The concentration of cholylglycine in serum of all patients was measured by radioimmunoassay (Abbott Laboratories, North Chicago, IL), ${ }^{14}$ and results expressed in micromoles per litre. Sensitivity, defined as the minimum concentration of cholylglycine detectable with $95 \%$ confidence from the zero dose, was determined to be $0.2 \mu \mathrm{mol} / \mathrm{l}$. Total nonsulphated serum bile acid concentration was determined, when adequate serum remained, by a modification of the 3-alpha-dydroxysteroid dehydrogenase method (Nyegaard and Co., Oslo, Norway), and results expressed in micromoles per litre. ${ }^{15} 16$

\section{STATISTICAL METHODS}

The data were expressed as mean values plus or minus the standard error of the mean. The fasting baseline for each subject was determined by averaging the values obtained at the -30 and 0 time points. The peak concentration (maximum rise above baseline) achieved by each individual at any time point was ascertained, a mean peak concentration for each group was calculated, and differences between groups were determined using analysis of variance. ${ }^{17}$ The areas under the meal response curves were calculated with the aid of a computer programme. The mean peak times and areas under the curves were compared using Duncan's multiple range test. ${ }^{18}$

\section{Results}

The meal response curve for patients with newly diagnosed, untreated ileal Crohn's disease is compared with the profile obtained in normal children (Fig. 1). The mean peak rise above the fasting baseline for the seven patients with radiological ileal involvement was $0.4 \pm 0.05 \mu \mathrm{mol} / 1$ for cholylglycine (Fig. 2); the increase in total serum bile acid concentration was $2 \cdot 1 \pm 0.5 \mu \mathrm{mol} / 1$ in the five patients studied (Fig. 3). These responses were similar to those seen in patients with ileal resection who had a mean peak rise in cholylglycine concentration of $0.3 \pm 0.09 \mu \mathrm{mol} / \mathrm{l}$ and a rise in the total serum bile acid concentration of $2 \cdot 2 \pm 0 \cdot 8 \mu \mathrm{mol} / 1$.

A significantly $(\mathrm{P}<0 \cdot 01)$ greater response occurred in 16 normal subjects, with a mean peak postprandial cholylglycine rise of $1.8 \pm 0 \cdot 18 \mu \mathrm{mol} / 1$ (Fig. 2). In a similar fashion, the mean total serum bile acid concentration rose postprandially by $9 \cdot 8 \pm 2 \cdot 4 \mu \mathrm{mol} / 1$ in

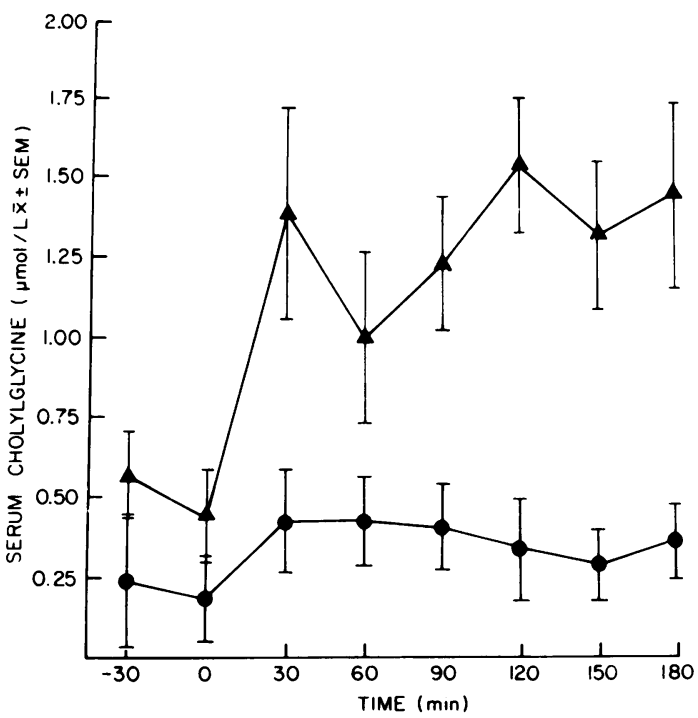

Fig. 1 Response of the serum cholylglycine concentration to the standard meal stimulus (mean rise above baseline) in normal $(\Delta$ children $(n=16)$ and in patients with newly diagnosed, untreated Crohn's disease involving the terminal ileum $(\mathrm{O}, n=7)$. The bars represent the mean $\pm S E M$ at each time interval. 


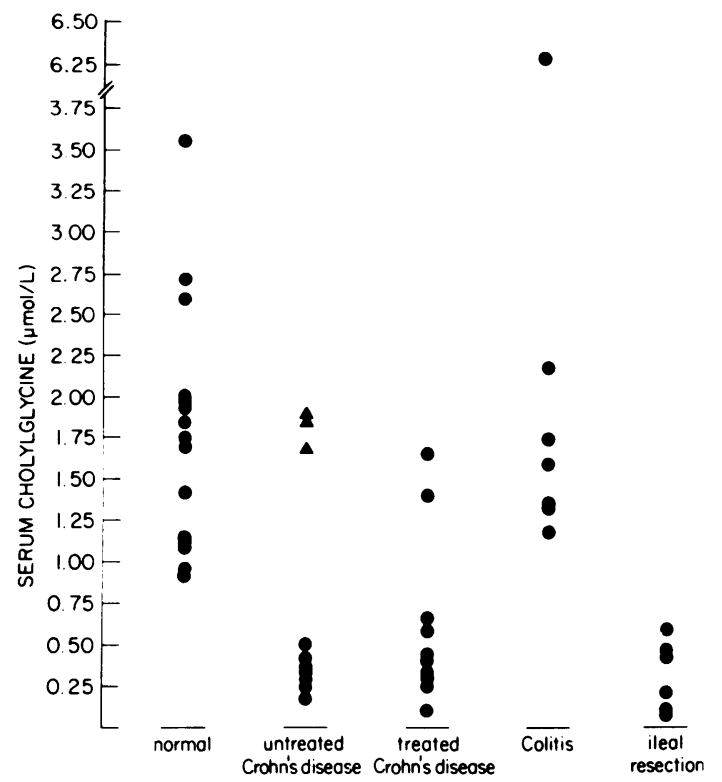

Fig. 2 Serum cholylglycine concentrations (mmol/l) after the standard meal stimulus in the individual patients in each group; expressed as the maximum rise above the fasting baselthe achieved during the three hour test period. $\Delta$ normal terminal ileum.

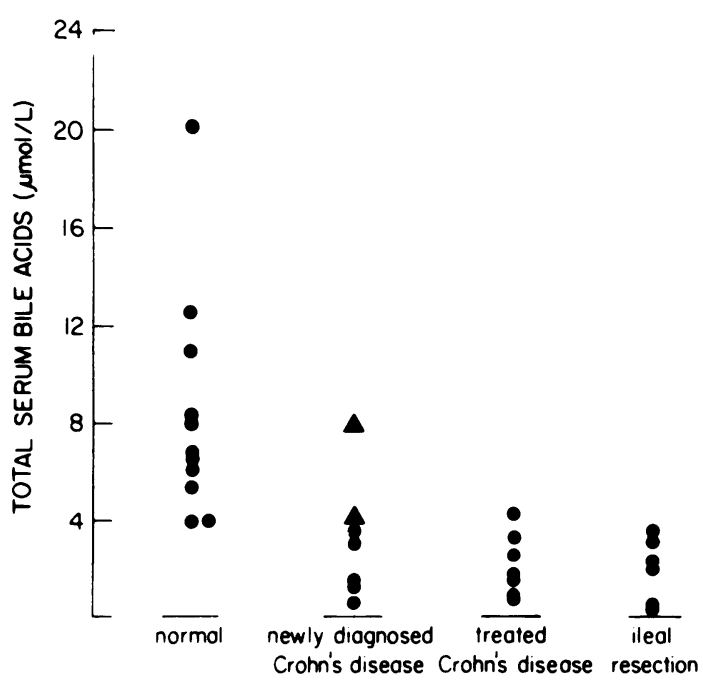

Fig. 3 Total serum bile acid concentrations ( $m m o l / l$ ) after the standard meal stimulus in the individual patients in each group; expressed as the maximum rise above the fasting baseline achieved during the three hour test period. $\mathbf{\Delta}$ normal terminal ileum.
11 of these subjects $(\mathrm{P}<0.025)$ (Fig. 3). In children with ulcerative colitis, the rise in cholylglycine of $2 \cdot 2 \pm 0.6 \mu \mathrm{mol} / 1$ was not significantly different from controls. In patients with newly diagnosed Crohn's disease in whom there was no radiological evidence of terminal ileal involvement the postprandial response was also similar to controls.

In the 10 patients with Crohn's disease treated for longer than six months (Fig. 2), the mean increase in cholylglycine concentration $(0.4 \pm 0.06 \mu \mathrm{mol} / \mathrm{l})$ was also significantly $(\mathrm{P}<0.01)$ different from normal. However, in two of three asymptomatic patients in this group, a normal postprandial rise occurred. The mean peak response of the total serum bile acid concentration in seven treated patients was $2 \cdot 2 \pm 0 \cdot 5$ $\mu \mathrm{mol} / \mathrm{l} \quad(\mathrm{P}<0.025)$; the maximum increases in two asymptomatic subjects from this group were not significantly different from the patients with active disease.

When all 14 patients with active Crohn's disease involving the terminal ileum are considered together, the maximum rise above baseline in cholylglycine concentration was $0.4 \pm 0.04 \mu \mathrm{mol} / 1(\mathrm{P}<0.01)$; total serum bile acid concentration rose $2 \cdot 0 \pm 0.4 \mu \mathrm{mol} / 1$ $(\mathrm{P}<0.025)$ in the 10 patients studied. There was no overlap in the mean values obtained in patients with active treated or untreated ileal disease and normal controls. There was no overlap seen in the mean response of patients with symptomatic colitis, including two patients with 'backwash' ileitis, or of patients with active Crohn's disease.

Examination of the meal response curves from the patients with active ileal Crohn's disease, from patients with active colitis, and from normal subjects revealed no significant differences in the mean time to the peak in the serum cholylglycine concentration $(1.69 \pm 0.25,2.08 \pm 0 \cdot 14$, and $1.68 \pm 0.21$ hours respectively). The integrated area under the meal response curve was similar in the colitis and normal groups $(5.4 \pm 1.4$ and $3.9 \pm 0.7 \mu \mathrm{mol} / 1 / \mathrm{h}$ respectively, $P$ not significant) but significantly less in the Crohn's disease patients $(1 \cdot 3 \pm 0.26 \mu \mathrm{mol} / \mathrm{l} / \mathrm{h}, \mathrm{P}<0.01)$.

\section{Discussion}

This study shows that ileal inflammation in Crohn's disease may interfere with the expected postprandial rise in the serum bile acid concentration. In all patients with active ileal disease, both the mean peak increase in the serum cholylglycine concentration and the integrated area under the meal response curve were significantly different from that seen in controls and similar to results obtained in patients with ileal resection. The findings are apparently specific for ileal dysfunction, as a normal rise in serum bile acid levels occurred in patients with Crohn's 
disease limited to the proximal small bowel and in patients with symptomatic colitis. Three patients with previously defined ileal involvement were studied during a period of clinical remission; a normal rise in serum cholylglycine concentration occurred in two of these patients.

Previous investigators have demonstrated an interruption of the enterohepatic circulation of bile acids in patients with Crohn's disease and have taken advantage of this altered physiology to assess ileal functional integrity. Daily faecal bile acid excretion has been variable in several studies and the degree of bile acid malabsorption has correlated with faecal volume. ${ }^{4}$ However, measurement of faecal bile acid concentration alone may not detect significant ileal disease, as the amount lost in the stool will vary depending on the bile acid pool size. ${ }^{19}$ This concept is in agreement with the data of Weber et al., who found that, among six children with ileocolic Crohn's disease, only one excreted an excessive quantity of bile acid in stool. ${ }^{20}$

Several studies have found rapid faecal excretion of ${ }^{14} \mathrm{C}$-labelled cholic acid given either intravenously or orally to patients with Crohn's disease. Faecal ${ }^{14} \mathrm{C}$-labelled bile acid output was excessive in 13 unoperated patients with Crohn's disease studied by Pedersen et al. ${ }^{21}$. Two of six subjects with inactive disease had faecal losses of the labelled compound comparable with normal subjects. Using a similar technique, Van Blankenstein et al. found bile acid malabsorption in 15 of 18 patients with ileal Crohn's disease. $^{5}$

The bile acid breath test (cholylglycine- $1-{ }^{14} \mathrm{C}$ ) has also been used to detect altered bile acid metabolism in patients with Crohn's disease. ${ }^{82}$ In patients with either bile acid malabsorption due to ileal disease or with bacterial contamination of the small bowel, rapid excretion of ${ }^{14} \mathrm{CO}_{2}$ in breath follows bacterial deconjugation of the labelled compound. Precise differentiation of these conditions requires measurement of ${ }^{14} \mathrm{C}$ excretion in expired air and in faeces. Thaysen and Pedersen reported a postive breath test in only 14 of 34 patients with terminal ileitis, while 31 patients had an increased faecal excretion of ${ }^{14} \mathrm{C}$. They concluded that the sensitivity of the combined assays in detecting ileopathy was superior to any other conventional tool including the Schilling test, faecal fat analysis, and radiographs. ${ }^{8}$

Van Trappen and associates studied bile acid composition and pool size in a group of 13 unoperated patients with Crohn's disease. ${ }^{7}$ The ratio of glycine to taurine conjugates was greater in these patients than in normal subjects, reflecting excess bile acid loss. The bile acid pool size was significantly decreased and, of all laboratory parameters, this change correlated best with disease activity as as- sessed by the National Cooperative Crohn's Disease Study Activity Index. ${ }^{13}$ Extent of disease as defined radiographically did not correlate with the activity score. Unfortunately, in this study there was considerable and unexplained overlap in pool size between patients with Crohn's disease and ulcerative colitis.

Alterations in the enterohepatic circulation of bile acids may be characterised from a number of vantage points; the numerous methods vary in their sensitivity, specificity, and ease of clinical application. Previous work has suggested that involvement of receptor sites for the active reabsorption of bile acids may occur in ileitis before more commonly regarded abnormalities are detectable. We chose to measure serum bile acid concentrations in Crohn's disease; our hypothesis being that, in the presence of ileal injury, less bile acid would enter peripheral blood in the postprandial state, and that this abnormality could be quantified and differentiated from the meal response in normal subjects.

The cholylglycine assay is particularly suited for use as a test of ileal function, as this compound relies predominantly on ileal active transport for reabsorption. ${ }^{23}$ Less polar bile acid species can be absorbed throughout the small intestine by passive transport mechanisms. This phenomenon might obscure subtle changes in the enterohepatic circulation when the total serum bile acid concentration is measured. In our study, total serum bile acid levels, as determined by the enzymatic assay, did afford satisfactory, but less striking, discrimination between the Crohn's disease group and normal subjects. In view of the possibility of false negative results and the cumbersome nature of the methodology, this assay seems less suited for clinical application.

We studied all patients after a 12 hour fast to ensure a best response after meal stimulated gallbladder contraction. The time required to reach a peak in the serum cholylglycine concentration is similar in all patient groups and suggests comparable intraluminal events such as gallbladder emptying and transit to the terminal ileum. The maximum rise in serum bile acid concentration is sufficient to distinguish all patients with active ileal Crohn's disease from normal subjects. The integrated area under the meal curve has been used by several investigators to compare the response of various patient groups, ${ }^{9} 12$ but in our study was not more sensitive than the easily derived peak concentration in detecting ileal dysfunction. It is possible that discrimination may be further enhanced by studying patients over a 24 hour period or after the third meal of the day to follow depletion of the bile acid pool, as might occur with each successive meal in patients with ileal dysfunction. ${ }^{9}$ Deconjugation of bile acids from bacterial 
overgrowth of the small intestine could also decrease the postprandial serum bile acid response; additional study of this problem is warranted in Crohn's disease.

Samuelson and associates have recently suggested that liver dysfunction in some patients with Crohn's disease could lead to raised fasting and postprandial serum bile acid levels and thereby invalidate the use of this measurement as a test of ileal inflammation. ${ }^{24}$ However, their group of patients is not comparable with our study population in that they had all previously undergone distal ileal resection. In addition, there is no attempt to correlate the meal response with Crohn's disease activity. It is possible that in the presence of mild liver dysfunction an accurate assessment of ileal integrity may still be obtained through observation of the rise above the fasting baseline instead of the absolute serum bile acid concentration.

In conclusion, our preliminary observations support the concept of an altered enterohepatic circulation of bile acids in Crohn's disease as has been suggested by previous studies. ${ }^{25}$ The defect in bile acid absorption is apparently specific for ileal involvement and active disease. Analysis of the postprandial serum bile acid response may be useful in evaluating insidious systemic and gastrointestinal complaints which may be seen in childhood ileitis. Additional studies are needed to judge the clinical usefulness of this determination in the diagnosis and serial assessment of patients with Crohn's disease.

\section{References}

${ }^{1}$ Suchy FJ, Balistreri WF. Ileal dysfunction in Crohn's disease assessed by the postprandial serum bile acid response. Gastroenterology 1979; 76:1256.

${ }^{2}$ Gryboski JD, Spiro HM. Prognosis in children with Crohn's disease. Gastroenterology 1978; 74:807-17.

${ }^{3}$ Stanley MM, Nemchausky B. Fecal ${ }^{14}$ C-bile acid excretion in normal subjects and patients with steroidwasting syndromes secondary to ileal dysfunction. $J$ Lab Clin Med 1967; 70:627-39.

${ }^{4}$ Meihoff WE, Kern F. Bile salt malabsorption in regional ileitis, ileal resection and mannitol-induced diarrhea. $J$ Clin Invest 1968; 47:261-7.

${ }^{5}$ Van Blankenstein M, Hoyset T, Horchner P, et al. Faecal bile acid radioactivity, a sensitive and relatively simple test for ileal dysfunction. Neth J Med 1977; 20:248-52.

${ }^{6}$ Mitchell WD, Eastwood MA: Faecal bile acids and neutral steroids in patients with ileal dysfunction. Scand $J$ Gastroenterol 1974; 7:29-32.

${ }^{7}$ Van Trappen G, Ghoos Y, Rutgeerts P, et al. Bile acid studies in uncomplicated Crohn's disease. Gut 1977; 19:730-5.
${ }^{8}$ Thaysen EH, Pedersen L. Clinical evaluation of the $\left({ }^{14} \mathrm{C}\right)$ cholylglycine breath test. In: Bile acid metabolism in health and disease, Proceedings of IV Bile Acid Meeting held at Hilton Hotel, Basel, Switzerland, October 11-12, 1976, Baltimore, University Park Press, 1977: 263-9.

${ }^{9}$ LaRusso NF, Korman MG, Hoffman NE, et al. Dynamics of the enterohepatic circulation of bile acids: Postprandial serum concentration of conjugates of cholic acid in health, cholecystectomized patients, and patients with bile acid malabsorption. $N$ Engl J Med 1974; 291:689-92.

${ }^{10}$ Ponz De Leon M, Murphy GM, Dowling RH. Physiological factors influencing serum bile acid levels. Gut 1978; 19:32-9.

${ }^{11}$ de Barros SG, Balistreri WF, Soloway RD, et al. Serum bile acids reflect physiologic changes in the enterohepatic circulation. Clin Res 1979; 27:271.

${ }^{12}$ Schalm SW, LaRusso NF, Hofmann AF, et al. Diurnal serum levels of primary conjugated bile acids. Gut 1978; 19:1006-14.

13 Best WR, Becktel JN, Singleton JW, et al. Development of a Crohn's disease activity index - National Cooperative Crohn's Disease Study. Gastroenterology 1976; 70:439-44.

${ }^{14}$ Miller P, Weiss S, Cornell M. Specific ${ }^{125}$ I radioimmunoassay for cholylglycine. Clin Chem 1978; $24: 999$.

${ }^{15}$ Gilhuus-Moe CC, Gogstad G. Methodological studies on a direct enzymatic fluorometric quantitation of total bile acids in serum. Fresenius $Z$ Anal Chem 1978; 290:181-2.

${ }^{16}$ Osuga T, Mitamura K, Mashige F, et al. Evaluation of fluorometrically estimated serum bile acid in liver disease. Clin Chem Acta 1977; 75:81-90.

${ }^{17}$ Kirk RE Experimental design: procedures for the behavioral sciences, Belmont, CA: Brooks/Cole Publishing, 1968; 90-1.

${ }^{18}$ Duncan DB Multiple range and multiple $F$ tests. Biometrics 1955; 11:1-42.

${ }^{19}$ Fromm H: Bile acid diarrhea. In: Internal medicine 1976 Topics 13th Int. Congr. Internal Med; Helsinki 1976, Basel: Karger, 1977: 29-38.

${ }^{20}$ Weber A, Roy CC, Chartrand L, Morin CL, et al. Malabsorption des acides biliares chez l'enfant, en l'absence de resection intestinale. L'Union Medicale du Canada 1974; 103:2089-94.

21 Pedersen L, Arnfred T, Thaysen EH. Rapid screening of increased bile acid deconjugation and bile acid malabsorption by means of the glycine-1-( $\left.{ }^{14} \mathrm{C}\right)$ cholylglycine assay. Scand J Gastroenterol 1973; 8:655-76.

${ }^{22}$ Fromm H, Hofmann AF. Breath test for altered bile acid metabolism. Lancet 1971; 2:621-5.

${ }^{23}$ Lack L, Weiner IM. Bile salt transport system. In: Nair PP, Kritchevsky D eds. The bile acids, vol. 2, chap. 2. New York: Plenum Press, 1973: 33-54.

${ }^{24}$ Samuelson K, Johansson C, Norman A. Serum bile acids after a test meal in Crohn's disease. Scand J Clin Lab Invest 1979; 39:511-8.

${ }^{25}$ Bálisteri WF, Suchy FJ, Heubi JE. Serum bile acid response to a test meal stimulus: a sensitive test of ileal function. $J$ Pediatr 1980; 96:582-9. 
ever-expanding subject which, from early student days, often seems to be clouded by mystique.

The layout and concise style are excellent and the content provides a refreshing insight into hepatology, with accepted dogma tempered throughout by the reality of every-day clinical experience. There is a generally critical approach to the more controversial areas of management, such as chronic active hepatitis, primary biliary cirrhosis, and portal hypertension. The chapter on immunology in liver disease is commendably concise and all that is needed by most clinicians.
No mention is made of nutritional aspects such as the new field of branch chain amino-acid therapy, or the role of ultrasound in diagnostic and therapeutic aspiration of liver abscesses. Also the advice concerning 'appropriate' antibiotics for liver abscesses is inadequate and Child's classification could have been properly described. The book is surprisingly up to date and overall is a valuable complementary addition of the tradition excellent large British texts on liver disease. I can recommend it wholeheartedly.

B J M JONES

\section{Books received}

Aspects of Gastroenterology for Nurses Edited by Mary Sykes. (Pp. 241. Illustrated. £17.50.) Pitman Medical: London. 1981.

Gastric Secretion: Basic and Clinical Aspects Edited by Stanislaw J Konturek and Wolfram Domschke. (Pp. 123. Illustrated. Price not stated.) Thieme: Stuttgart. 1981.

Stomach Diseases. Current Status. Edited by Y M F van Maercke, E M J van Moer, P A R Pelckmans. International Congress Series 555. (Pp. 434. Illustrated. \$76.50.) Excerpta Medica: Amsterdam. 1981.

\section{Corrections}

Ileal dysfunction in Crohn's disease assessed by the postprandial serum bile acid response by F J Suchy and W F Balistreri, Gut 1981;22:948-52. In the legends of Figs 2 and 3, the units should $\mathrm{read} \mu \mathrm{mol} / \mathrm{l}$, not $\mathrm{mmol} / \mathrm{l}$. In the last paragraph of the Results section, the integrated area under the meal response curve should be $\mu \mathrm{mol} / \mathrm{l} . \mathrm{h}$ and not $\mu \mathrm{mol} / \mathrm{l} / \mathrm{h}$.

Gastric mucosal histamine and histamine methyltransferase in patients with duodenal ulcer by $\mathbf{N} \mathbf{R}$ Peden, Helen Callachan, D M Shepherd, and K G Wormsley, Gut 1982; 23:58-62. All the signs indicating the $P$ values in this article were printed as greater than and should have indicated less than the appropriate value, except for $0.1>P>0.05$ on page 59. 